\title{
Creating Transcriptions and Adaptations for Viola in Kazakhstan: Retrospection, Theory and Practice
}

\author{
Aizhan S. Bekenova', Gulnar B. Abdirakhman², Diana Ye. Mahmood³, Arita B. \\ Baisakalova ${ }^{4}$ \& Alma A. Abatova ${ }^{5}$ \\ 'Doctoral Student, Kazakh National Conservatory, Almaty, Republic of Kazakhstan. \\ Email: aizhans.bekenova@mail.ru \\ ${ }^{2}$ Candidate of Arts, Kazakh National Conservatory, Almaty, Republic of Kazakhstan. \\ 3 Doctor of Philosophy (Ph.d), Kazakh National Conservatory, Almaty, Republic of Kazakhstan. \\ ${ }^{4}$ Professor, Kazakh National Conservatory, Almaty, Republic of Kazakhstan. \\ ${ }^{5}$ Associate Professor, Kazakh National Conservatory, Almaty, Republic of Kazakhstan.
}

\begin{abstract}
Starting from the past century, viola began to draw much interest of musicians, performers and musicologists, as it gradually acquired a new role of a solo instrument. Although these days more compositions appear written especially for this instrument, the independent role of viola was always accompanied more with transcriptions and adaptations of works composed for other related instruments, mostly violin, cello, etc. This article looks into the history and perspectives of making transcriptions for the viola in the Kazakh musical culture. The study also involves the analysis of Kazakh viola schools with a focus on their founders. Questions of the history and theory of viola transcriptions are still waiting for detailed scientific understanding. The work of musicians who successfully applied to transcriptions and adaptations in their practice and formed the technology of this creative process has not been sufficiently studied. It requires more in-depth study and can be used as a practical guide for the work of other musicians. This determines the relevance of this article.
\end{abstract}

Keywords: transcriptional work, musical arrangement, Fudiman, viola school, folk music, repertoire.

\section{Introduction}

The world history of the viola begins with the end of the 16th century, when this instrument was often used in ensemble and orchestral music. Its main function was the melodic filling of the middle voice in the texture, which led to its interpretation by the composers and performers as a nondominant instrument in the overall picture of ensemble sound. This approach resulted in the lack of attention to the acoustic and expressive capabilities of the instrument (Zaytseva, \& SushkovaIrina, 2018).

(c) AesthetixMS 2020. This Open Access article is published under a Creative Commons Attribution Non-Commercial 4.0 International License (http://creativecommons.org/licenses/by-nc/4.o/), which permits non-commercial re-use, distribution, and reproduction in any medium, provided the original work is properly cited. For citation use the DOI. For commercial re-use, please contact editor@rupkatha.com. 
The technique of playing stringed instruments reached a fairly high level with the development of instrumental concerting in Europe in the second half of the 18th century, and it was in concerts that composers revealed these possibilities to the full. New artistic challenges related to the scale and virtuosity of the solo performance caused changes in the way the viola is held and some improvements in its construction, which made it easier to perform technically difficult parts (Darda, 2014). At the end of the first stage of its formation as an instrument capable of conducting solo concerts, the viola acquired almost modern appearance and, as rightly stated Kuznetsov (1977), "what was available at first only to virtuosos, people of high performing culture, later became available to a fairly wide range of performers."

The formation of viola performance in countries that did not have traditions of playing this instrument in their national culture necessitated creation of their own national repertoire for the viola. This task was addressed mainly through the adaptation of national music created for other performing conditions to viola performance. In the zoth century, Russia, Kazakhstan, Kyrgyzstan, Azerbaijan and other former Soviet republics followed this path. The formation of viola performance there was accompanied by the creation of transcriptions and adaptations of samples of folk music in order to form and expand the national concert and instructional repertoire.

The path of updating viola music through the creation of transcriptions of works for other instruments dates back to the 18th century, and for instruments such as the lute, keyboard instruments, compositions were transcribed mainly from vocal works. The early history of transcription practice stretches back to the 14th century.

Once the dimensions of the viola were standardized in the late seventeenth century, composers were inspired to write more works in solo and ensemble settings that featured the viola, but still, remarkably few in comparison to violin or cello. Printed method books for viola emerged in the late 17th and early 18th centuries, signifying its increasing importance. In the 19th century, the emergence of more music schools and conservatories, as well as prominent viola teachers and performers, further elevated the stature of the instrument (Mondragon, 2018).

Since the viola acquired the status of a solo instrument quite late, a significant part of its repertoire consists of adaptations and transcriptions of musical works originally created for other instruments, first of all, for the violin and various related instruments, although the object of transcription is often working for other European classical and folk instruments, as well as vocal and choral music. As was pointed out by Kurys (2016), transcriptions had the possibility to increase the visibility of the viola and art music written for it in a wider market and was integral moving it forward as a solo instrument in the beginning of the 2oth century. It was used as a tool to reach new audiences and help make the connection of relevance to those that were uninitiated in the genre.

According to G. M. Kogan, L. I. Roizman (1973), and other researchers of this problem, transcription acquired independent artistic significance in the time of J. S. Bach. The great German composer, in view of the number of his adaptations, probably took considerable pleasure in rearranging for the clavier and various ensembles the works of Italian and German composers, among whom were both his predecessors and contemporaries (Klimova, 2013).

This way of expanding viola literature has remained relevant in the artistic practice of the 21st century. This is despite the fact that the viola repertoire has grown considerably in the past century. The new interpretation of stringed folk instruments was determined by the possibility of a new interpretation of samples of world music classics, as well as modern compositions, since the specific timbre of folk instruments, "installed" in the context of modern intonation, acquired a new semantic meaning (Pchelintsev, 2018). Now it has hundreds of highly artistic works created especially for this 
instrument. Most often, works from the cello repertoire are used as material for viola transcription, since this is the closest string instrument to the viola in terms of tuning. Violin music is also in high demand, as well as works from the repertoire of wind instruments similar to the viola in timbre clarinet, bassoon, French horn, and vocal works. Meanwhile, questions of the history and theory of viola transcriptions are still waiting for detailed scientific understanding. The work of musicians who successfully applied to such techniques in their practice and formed the technology of this creative process during the creation of transcriptions has not been sufficiently studied. It requires more in-depth study and can be used as a practical guide for the work of other musicians. This determines the relevance of this article.

\section{Literature review}

Questions related to the history of viola music, its genre composition, and the development of national viola schools have repeatedly appealed to the interest of musicologists. The fundamental works of musical and historical focus include the works of Moisey Greenberg "Russian Viola Literature" (1967), S. Ponyatovskiy, "History of Viola Art" (2007), thesis by V. Gorbunov "Russian Viola Art of the 18th - Early 2oth Centuries (Instrument, Scope of Use, Composer Creativity)" (2004), thesis by S. Marshanskiy "Viola Art of Russia of Second Half of the 2oth - Beginning of the 21st Century" (2012), thesis by V. Yuzefovich "V. V. Borisovskiy - the Founder of the Soviet Viola School" (1977), as well as thesis by M. Riley "History of the viola" published by Braun-Brumfield in 1980 and 1991 in two editions.

In Kazakhstan, this problem was addressed by the violist-practitioner N. Sagimbaev, who teaches at the Department of String Instruments of the Kurmangazy Kazakh National Conservatory. The results of his research are reflected in the book "The History of Viola Performance in Kazakhstan" (2015). The peculiarity of all these works is that they consider the development of the viola and viola art in close connection with the formation of national viola schools. Therefore, a significant part of them is devoted to reviewing the performance of musicians who have made a significant contribution to the development of viola art in their country.

Interest in transcriptions in viola music is reflected in the works by V. Klimova (2011) and Hsiaopei Lee (2005), Rachel White Galvin (2013), and others. Russian researcher V. Klimova considers this issue on the example of the work of the representative of own national school of viola performance V. Borisovsky, who is the author of numerous transcriptions for the viola. Hsiaopei Lee in her work justified the approaches to own transcriptional work on the example of the analysis of the transcription of the Violin Sonata Op. 30, No. 1 by L. Beethoven. The author offers a brief history of the genre and focuses on the experience of transcription of the violin sonatas of Beethoven from the point of view that this work will considerably add to the lack of solo viola literature from composers of the transitional period from classical to romanticism, thus expanding the repertoire for viola performers and giving to the teachers of the viola class and chamber ensemble a larger range of note-music literature, with the goal of solving educational tasks in the study of the music style of the early 19 th century.

An important work on the problems of viola transcription is Rachel White Galvin's study "Viola Transcriptions: History, Rationale, and Process, with Focus on Selected Works by August Halm" (2013). In this work, the author defines a set of general principles that the author can use in the practical work on creating a transcription of a violin work. The study material for Rachel White 
Galvin were two sonatas for violin and piano, as well as three solo sonatas for violin by German composer August Halm. This work is worth attention, first of all, due to its practical orientation, since it describes the experience of transcribing violin works by a violist who knows all the details of the instrument.

To further understand the essence of transcriptional activity, we have also studied a number of works on the history and theory of the transcription genre based on music for other instruments. These include works by N. Davydov "Methodology of transcription of instrumental works for Bayan" (1982), dissertation research by B. B. Borodin "Phenomenon of Piano Transcription: Experience of a Comprehensive Study" (2006), N. P. Ivanchey's "Piano Transcription in the Russian Musical Culture of the 19th century", M. Parshin's "Development of the Art of Concert Balalaika Transcription" (2013), articles by G Kogan “On Transcription” (1972) and others.

\section{Materials and Methods}

The aim of our research is to study the scientific and musical literature for viola, to examine the history of viola performance and transcriptions for viola in Kazakhstan, as well as to identify and describe the existing approaches to creating transcriptional works for viola in musical practice. The research material was samples of viola transcriptions presented in foreign and Kazakh musical literature: anthology for viola "Works of Long Form" (2001) by L. Gushchina, E. Stoklitskaya; anthology for viola "Musical Pieces, Works of Long Form, Ensembles" (1985) by M. Reitih; in musical collections "Pieces for Violin and Kobyz" by A. Nurbayev; "Pieces for Viola and Alto Kobyz" by Ya. I. Fudiman (1981); "Works of Kazakh Composers for Viola and Piano" edited and transcribed by N. Karimov (2007); “Collection of Pieces of Kazakhstan's Composers" arranged for viola and piano by D. Mahmood (2006); manuscript of the piece "Kos-Alka” transcribed by Ya. I. Fudiman; concerto for cello and orchestra by E. Brusilovsky transcribed by E. Liberchuk; Concerto for kobyz by A. Zhayymov and others. The work with musical material was based on the use of methods of musicological, performing analysis and the method of comparing the original work with transcription.

\section{Results and Discussion}

\section{Historical aspect of the problem}

To date, Kazakhstan has accumulated considerable practical experience in expanding the viola repertoire by creating various kinds of transcriptions of musical works for other instruments. Many of them are form a part of the educational, pedagogical and concert repertoire of violist performers. The creation of the Kurmangazy Almaty State Conservatory in 1944, which was accompanied by great organizational and technical difficulties, played a chief role in the establishment and development of the viola school in Kazakhstan. There was not enough space prepared for classes, high-quality musical instruments, and sufficient musical material in the library. For the first few years, there was no viola class at the Conservatory. In February 1947, at a regular meeting of the String Department, the question of introducing mandatory viola classes for violin students was raised. Veniamin Solomonovich Hess was invited as a teacher from the Almaty Tchaikovsky Music School (Karimov, 2010).

V. S. Hess played a critical role in the development of all levels of educational and performing infrastructure in Kazakhstan. The subject matter of V. S. Hess's reports on the theory and history of performance, as well as the methodically developed and justified concept of his pedagogical 
observations, is emblematic. Kazakh National Conservatory for a period of seventy years actively worked on the formation of all educational levels. Contacts with children's musical schools, colleges and higher education institutions contributed to the formation of primary, secondary and higher music education in Kazakhstan, taking into account European and national traditions (Zhumabekova, 2015).

The history of viola art in Kazakhstan goes back to the 1930-40s. This period has entered the Republic's history as the first stage of mastering the laws of European classical music, its genre system and forms of music making. The urgent need of the stage was to train musicians who are able to perform world music, classics of different genres and styles at the proper level, as well as to create compositional music in the traditions of European classics. These tasks were solved by engaging experienced performers and composers from the "center" of the former USSR, mainly from Russia. Thus, in 1930-40s, promising string performers arrived in Kazakhstan. Among them were I. Ryk (1934), who is a graduate of the St. Petersburg (Leningrad) Conservatory, I. Lesman (1935), who is a student of the famous violinist L. Auer, G. Tansky (1936), E. Antopolsky (1937), who is a graduate of the Paris Conservatory. All of them played an important role in the formation of Kazakhstan's violin and viola performing schools. In addition to the special violin class, they also conducted a compulsory class of "viola", and also were actively engaged in concert activities, performing solo concerts in the Kazakh State Philharmonic orchestra, in the National Opera Theater as members of a String Quartet (I. Ryk and G. Tansky) and orchestra artists (V. Korepanov and A. Anisimov).

By the 1950s, the issue of creating a national viola repertoire was particularly acute. The circle of violist musicians in the Republic has significantly expanded, the educational process has entered a stable path, but Kazakh composers have not actually created music for the viola. In the pedagogical and concert repertoire, transcriptions and adaptations made by Russian violists-performers V. Borisovsky, E. Strakhov, etc., were in great demand. But these works could not fill the gap associated with the lack of a national repertoire. This stimulated the interest of Kazakh violist teachers in independent creative activities aimed at creating transcriptions and adaptations. As a result, during the development of transcriptional practice, the corpus of "Kazakh works for viola" gradually began to form. At the initial stage, these were violin works by Kazakh composers transcribed for viola, as well as adaptation samples of Kazakh traditional music - vocal (songs) and instrumental (kyuis).

The study of the history of the formation of the national repertoire for the viola allowed identifying a number of key figures who played an important role in this process. Thus, the 1950-1960s are associated with the name of Efim Liberchuk - a student of I. A. Lesman and V. S. Hess in the viola class. In 1958, he was one of the first to create transcriptions of Kazakh works and transcribed such violin pieces as "Prelude” by K. Musin, "Elegy” by K. Kuzhamyarov and "Melody" by V. Velikanov.

The 196os was the time when appeared the first professional Kazakh violist Ahan Nurbaev. Similar to most violists of that time, he started as a violinist, having graduated from the Alma-Ata Tchaikovsky Music School in the violin class. The Second World War interrupted A. Nurbaev's plans to perform as a professional musician on the stage, and after it was ended, the violinist-war veteran entered the Alma-Ata Conservatory, which opened in 1944, in the class of V. Hess. After graduation, A. Nurbaev played in the orchestra of the National Opera Theater of Alma-Ata (now Almaty). In 1957, the Republic was preparing for an important cultural event - the Second Decade of Kazakhstan's Art in Moscow. The orchestra, which was supposed to participate in this event, did not have violists, and Nurbaev began to master a related instrument. Later, as he became a viola teacher, he worked for a long time as the head of the String Instruments Department at the music school in Alma-Ata. In 1964, A. Nurbaev prepared for publication his "Collection of Adaptations of 
Kazakh Folk Melodies for Viola and Piano", which received high praise and approval in the conservatory community and is still popular in the pedagogical use.

The years 1980-1990 were marked by the creation of transcriptions for the viola of works of major genres: E. Liberchuk created a transcription of the Concerto for Cello by E. Brusilovsky (1981). During the same period, a professionally bright violist and teacher Yakov Fudiman published a collection of "Pieces for Viola and Alto Kobyz", which included adaptations of "Melody" by $\mathrm{H}$. Tastanov, "Kenes Kyui" by K. Mukhitov, "Leaf from the Album" by K. Kuzhamyarov, "Romance" by M. Koyshibaev and "Themes with variations" by G. Zhubanova.

The role of Y. Fudiman in the development of viola performance in Kazakhstan and in creating a repertoire for this instrument is hard to overestimate. Being the founder of the national viola school, he raised numerous musicians-violists, who later represented his school not only in Kazakhstan, but also abroad. He made a huge contribution not only to the development of viola performance and training, but also to the expansion of the viola repertoire. His work in creating transcriptions and adaptations was undoubtedly based on a great performing experience and mastery of the viola.

Analyzing the adaptations conducted by Fudiman, it is possible to state that his approach to the adaptation of the original source is based on the organic synthesis of creative and performing tasks. The viola versions are always carefully worked-through from the stroke, fingering and dynamic perspective. At the same time, they preserve the thematic and structural basis of the original source. This approach can be called "performing", because it is difficult to implement it without a deep and comprehensive knowledge of the acoustic, technical and expressive capabilities of the instrument. On the other hand, Fudiman demonstrates penetration into the specifics of the instrument for which the original was written. This allows "imitating" of the nature of the sound of the original instrument, to be closer in its interpretation to the original.

In the last third of the 2oth - early 21st centuries, Fudiman's work passed to his students, who continued the line of creating transcriptions and adaptations of works for the viola. During his lifetime, the musician left not so many published works, but his recommendations, voiced in classes, among his students and followers, became the methodological basis for their activities. In 2006, the "Collection of Pieces by Composers of Kazakhstan" was published in an adaptation for viola and piano, prepared by Fudiman's student D. Ye. Mahmood, a graduate of the viola class of the Kurmangazy Kazakh National Conservatory (in 2018, it was reissued with the same name). And in 2007, the collection "Works of Kazakh Composers for Viola and Piano", prepared by Professor of the Kazakh National University of Art, an older Fudiman's student N. Karimov, was published. The basis of the latest collection consisted of chamber works by Kazakh composers and musicians of different generations, including original music for viola (G. Zhubanova's "Four Pieces for Viola Solo", S. Tuyakova's "Romance" and "Keruen") and transcriptions made by N. Karimov himself ("Romance" by A. Mettus, "Kyui" by M. Sagatov, "Poem” by K. Kumysbekov). Being an experienced teachermentor, in the introduction to the collection, the author explained his interest in creating transcriptions for viola by the lack of educational and pedagogical material necessary for the education of professional violists who possess a fairly wide range of skills and modern performing techniques (Karimov, 2007).

The study of the transcriptions made by N. Karimov made it possible to determine the strict academism in his approach to adapting the original source to new performing conditions. The transformation of the original is limited to stopping at a convenient tonality for playing the viola ("Kyui" by M. Sagatov, "Poem" by K. Kumysbekov). At the same time, the interpreter usually refers to the original literature for instruments related to the viola - violin and cello, focusing on the 
variety of performance techniques presented, including the technique of double notes and chords, various methods of modern sound production, and fingering and stroke complexity.

In N. Karimov's works, there is an obvious desire to follow the author's idea exactly, to preserve the expressive properties of the original musical material. Editorial changes, which abound in the text of viola versions of author's works made by N. Karimov, demonstrate the "Fudiman's approach" to details, design of strokes and fingerings, and indicate the continuity of the musicians' work aimed at expanding the viola repertoire.

A representative of the younger generation of violist students of Fudiman is Diana Mahmood. The "Collection of Pieces by Composers of Kazakhstan transcribed for Viola and Piano", published under her editorship, includes her transcriptions of popular violin and cello works by composers of Kazakhstan: A. Zhubanov, M. Tulebaev, E. Brusilovsky, K. Kumysbekov. The choice of these works cannot be called random. Each of them has become a classic of Kazakh music, entering the repertoire of many famous performers. In addition, the choice of works is due to the nature of the sound of the viola, its melodiousness, a special muted "mysterious" sound, close to the national timbre ideal. The analysis of transcriptions performed by D. Mahmood also demonstrates the reliance on the methodological and practical basis for creating transcriptions for viola, established by Fudiman.

\section{Theoretical aspect of the problem}

Creating an arrangement of a musical composition is a creative process. As the violist Watson Forbes points out, this is a matter of taste: "An arrangement can be a simple transference or an elaborate transcription... It is a matter of opinion how far one can go in adapting the original to its new form" (Forbes, 1979). But, in any case, this process is based on the desire to preserve the ideological and artistic content of the work, taking into account the new instrumental conditions. The question of the quality and completeness of the transfer of the artistic content of the original source is of paramount importance.

Another important point when working on the transcription of a work for a solo instrument is to observe the most important principle of the transcription - "playability" and ease of performance. In order to achieve this, the authors of transcriptions resort to a variety of methods: easing the texture, changing the tonality, octave transfers, the use of double notes, chords, careful placement of fingering, nuances and dynamic shades, the use of a variety of bow playing techniques.

The analysis of numerous transcriptions for viola shows that the effective solution of artistic tasks largely depends on the selection of musical material for transcription. To a lesser extent, this applies to works for other stringed instruments, since their specificity is close to the viola. But, despite this, the world-famous violist W. Primrose warned that often what sounds great on the violin is not acceptable for viola performance (Dalton, 1988). This is due to the fact that the virtuosity of violin opuses can be an obstacle to the disclosure of the unique expressive capabilities of the viola and even contradict them. When transcribing piano works or samples of music for wind and folk instruments, the specificity of the original instrument comes to the fore. For example, piano compositions with a wide range, may not sound with a fine pedalized texture on the viola, because the range span will hinder maintenance of the evenness of the viola timbre. Compositions written for more than two instruments, an ensemble, trio or quartets, etc., are almost impossible to convey by means of the viola, although there are fewer stylistic contradictions in this case than in transcriptions of piano pieces. It is possible to transcribe for the viola works which texture does not correspond to the capabilities and specifics of the instrument, but it requires a deeper and more detailed approach. However, the result may not worth the effort. 
Thus, the process of selecting a sample for transcription largely depends not only on its artistic merits, but also on the quality of the musical material, its compliance with the specifics of the sound and technical capabilities of the viola. The main principle when choosing a piece, along with its aesthetic value, is its ability to reveal the best qualities of the viola, to show its uniqueness and expressive properties.

Following this principle determines the need for the transcriber to clearly represent the differences between the original instrument and the viola. When choosing a particular piece composed by a composer for one or more musical instruments, one must first imagine how it will sound on the viola. Also important are the answers to the questions: will this sound change the original intent of the composer? What level of training of the performer or listener does the transcription focus on? In the case of transcription intended for children, it is allowed, for example, a simplified presentation of musical material. The concert repertoire implies a different approach, aimed at the stage performance, with all the arising nuances in the use of the expressive possibilities of the viola.

A study of the extensive transcription literature for viola has shown that there is currently no standardized practice for creating transcriptions for solo instruments. Each author of transcriptions in the course of creative practice develops their own vision of the process and result, which, in the end, allows us to talk about their patterns. In the Russian school, such patterns are revealed in the work of V. Borisovsky, the author of more than 250 transcriptions for viola. There are three types of transcriptions in his work:

1. The ones that are as close as possible to the original text (timbre transformation);

2. The ones showing more distant links to the source text (a variant of interpretation while preserving the original intent);

3. The ones that totally modify the original source (affects not only the melodic and harmonic, but also the compositional side, and as a result the meaning of the original is changed).

The researcher V. Klimova, who has studied in detail the specifics of V. Borisovsky's transcriptions for viola, states that in his work transcriptions of the second group prevail. The first category of adaptations is presented in single editions that belong to the early period, and the third group is small in number, and is connected with his own composer's opuses (paraphrases on the themes of French melodies "Song of Rose", a suite from French dances "Romanesca”).

The figure of Yakov Fudiman is emblematic in the Kazakh tradition. The task of creating a national viola repertoire, which was set before the musician, determined the priority of using samples of folk music as a material for transcription. In this case, the variants of the transcriptions created by him are limited to type 1 and type 2 . Now we consider as an example one of the early works of Fudiman, a transcription of the Kazakh dombra kyui "Kos-Alka", that belong to Dauletkerey, the folk professional composer-kyuishi of the 19th century. The theme of this lyrical work is connected with the feminine principle, with the image of a girl whose smooth gait is accompanied by the rhythmic swaying of woman's jewelry - earrings and necklaces. This image is created primarily by means of a uniform swinging rhythm of eighth and quarter notes, as well as by means of a smooth melody line based on a circular ascending-descending movement in the fifth (Fig. 1). 


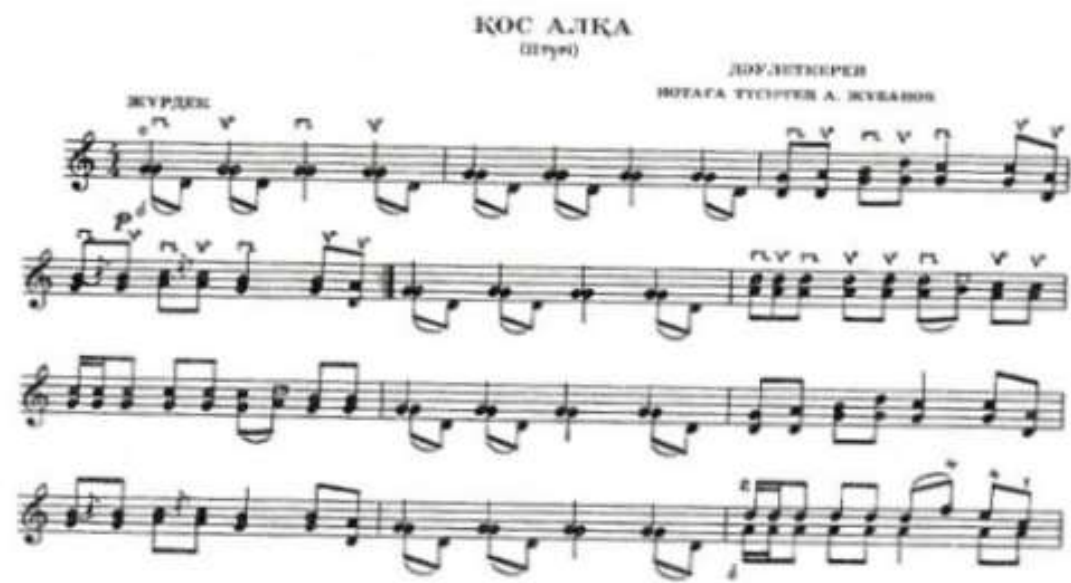

Figure 1. Dauletkerey's kyui “Kos-Alka” in musical notation by A. Zhubanov: bars 1-12

The original of the work has a "form with transposition" - tokpe, which is characteristic of the Kazakh dombra kyuis of the West Kazakhstan performing style. It is based on the change of modal bases (D-G; G-C; D-G), which gives not a thematic, but a timbre-register comparison of the extreme and central sections. This creates a monothematic 3-part kyui composition, which is completely preserved in the viola version.

The author of the adaptation preserves the shape and modal structure of the original source, and the resulting possibility of using empty strings on the viola (D-G) in a characteristic rhythmic design creates an atmosphere of unhurried motion, and swaying (Fig. 2).

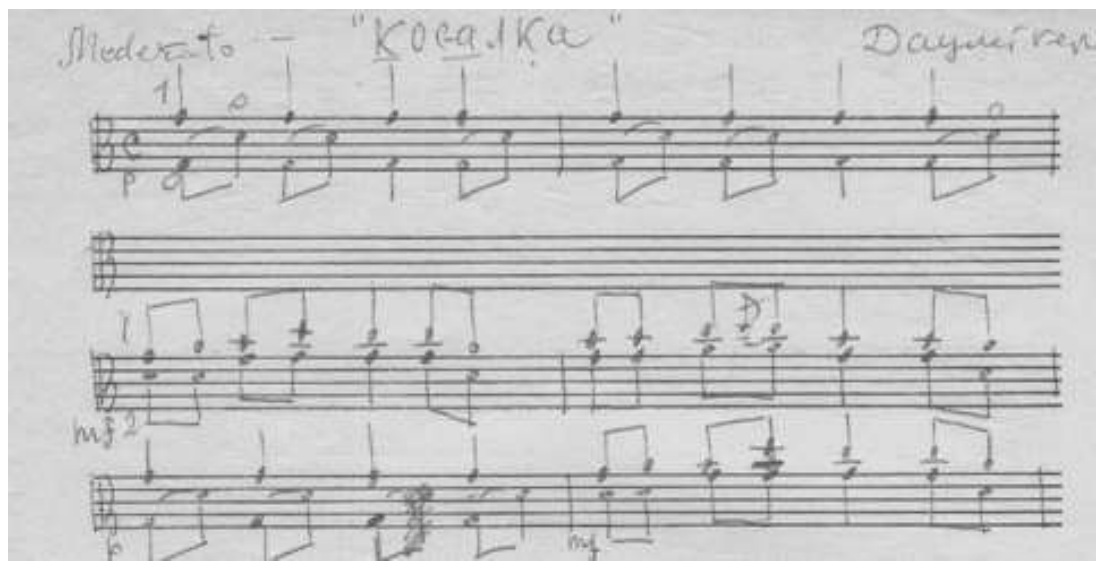

Figure 2. The fragment of Fudiman's manuscript of the kyui "Kos-Alka”: bars 1-6

The version of Fudiman clearly demonstrates following the patterns of the genre of folklore adaptation, suggesting a "preserving" approach in the interpretation of the folk original source. At the same time, all episodes of the viola kyui are meticulously designed in dynamic terms (scale from $\mathrm{p}, \mathrm{mf}$ to $\mathrm{f}$ ). This allows the performer and listener to easily perceive the syntactic structures formed during the interaction of repeated and new motives and phrases.

Yakov Fudiman resorts to classical methods of enhancing the expressiveness of the melodic line, which is "based on the natural connection of the ascending movement with the increase of tension, the descending one - with the decline, calming" (Mazel, \& Tsukkerman, 1967). In the culminating part of the kyui - the central moment of the work in terms of meaning - the Maestro makes it 
possible to more clearly convey the very nature of the culmination. He resorts to separate detache, close to the performing approach "ilme" on dombra, giving a playful character (Fig. 3).

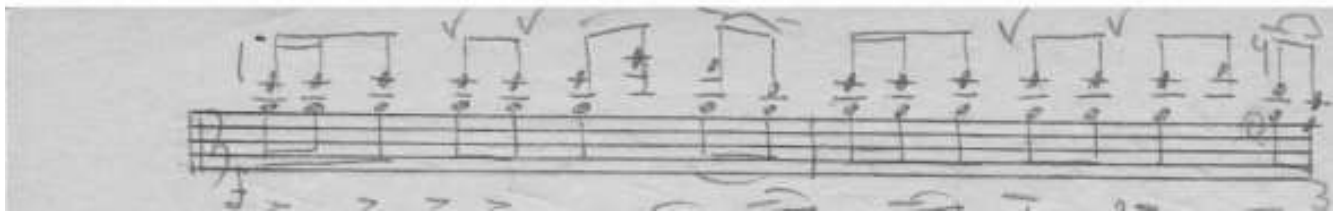

Figure 3. The fragment of Fudiman's manuscript of the kyui “Kos-Alka”: bars 9-10

In the final episode of the dombra kyui, the sound gradually calms down by the "melting" of the swaying rhythm (Fig. 4).

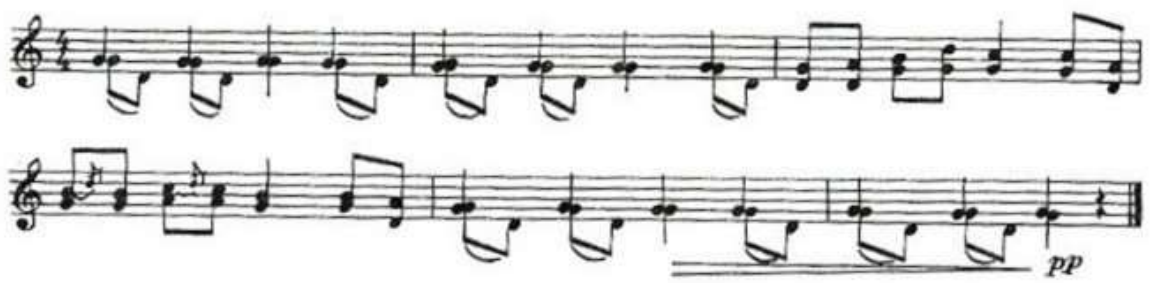

Figure 4. The fragment of the final episode of the kyui "Kos-Alka" notated by A. Zhubanov: bars 61-66

In the viola version, in the final episode of kyui, the effect of "fading sound" is achieved through the appropriate use of flautando technique (Fig. 5).

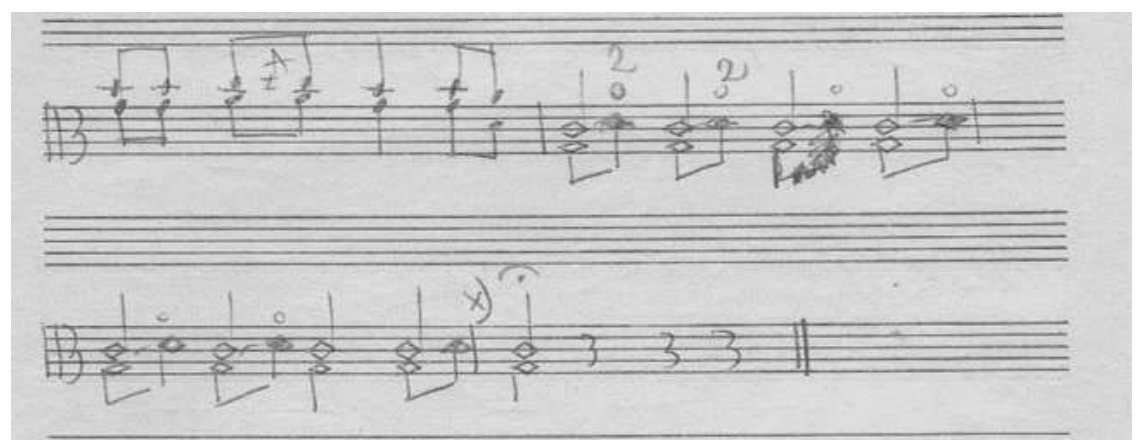

Figure 5. The fragment of Fudiman's manuscript of the kyui “Kos-Alka” (final episode): bars 73-76

Another interesting and often performed sample of the transcription made by Fudiman is the "Melody" of H. Tastanov, written in the original for the Kazakh folk stringed instrument kobyz (Fig. 6). This piece attracted the attention of Yakov Fudiman as "the material that is artistically interesting and melodically fruitful" (Fudiman, 1980), moreover, it is brightly colored nationally. The author of the original "Melodies" is a connoisseur of folk music, the master of performing dombra Kazakh kyuis H. Tastanov, managed to creatively rethink the tone fund of the Kazakh folk lyric song and create a melody as close as possible to the traditional one. The "circular" tone movement based on chants alternating with expressive jumps to a quart and a fifth, as well as the use of non-square scale-thematic structures, cause direct associations with the best examples of song lyrics of oral-professional musicians of the 19th century - Ahan-Sera, Ibray, Aset. 


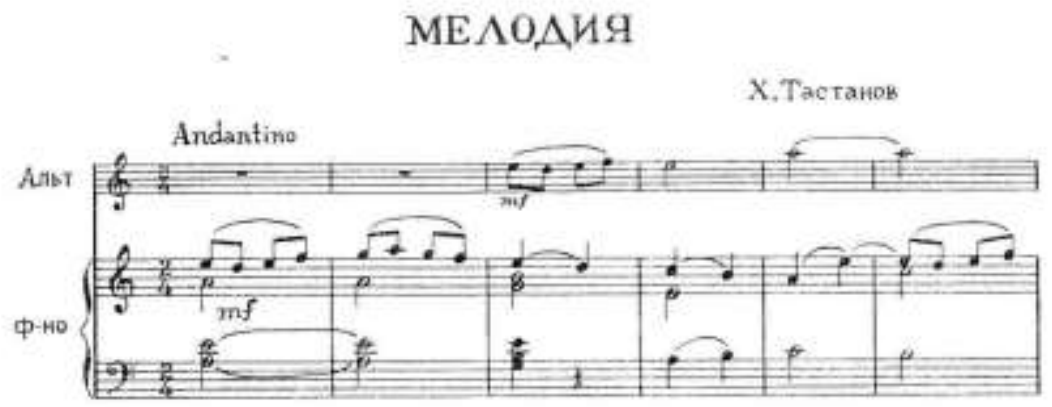

Figure 6. The fragment of H. Tastanov's "Melody" transcribed by Fudiman: bars 1-6

Fudiman achieves the cantilena nature of the melody on the viola through the smoothness, continuity of moving the bow, the use of vibration transmitted from finger to finger. The solo instrument and the piano part make up an intercomplementary duet, which flexibly uses the possibilities of imitation and contrasting polyphony with the participation of two to four voices, supplemented by peculiar harmonic bases of the quarto-quinto and tertian structure. In the preserved manuscript of a methodical orientation, explaining the nuances of this piece, Fudiman stresses inherent to it "nature of free improvisation, which is not broken even by signs of three-part recapitulation" (Fig. 7).

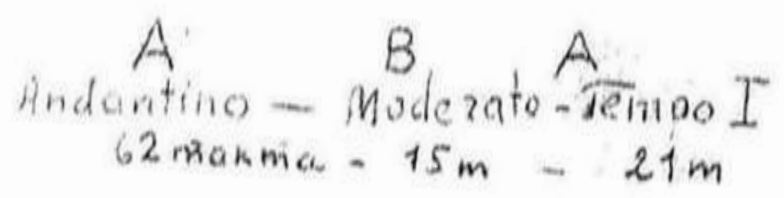

Figure 7. "Melody" by H. Tastanov (manuscript fragment of Fudiman)

In the viola version of the work, much attention is paid to the fingering, which is an important means of providing a smooth cantilena sound necessary for the transmission of a lyrical image. Fudiman was convinced that the "perfection of positional transitions" (Fudiman's concept (1980, p. 5)) can give a musical phrase a unique nuance: make it light, airy, or, on the contrary, tighten the sound, make it voluminous, tense. In the viola interpretation of "Melody", the emphasis is on frequent alternation of fingers, the use of finger span, the approach of "pushing" simultaneously with the change of the bow, the combination of vibrato technique with positional transitions and smooth legato. All this is aimed at concretizing the genre specificity of the work, in this case - at emphasizing its song basis.

\section{Conclusions}

The formation and development of national performing viola schools in post-Soviet Central Asian countries were accompanied by the creation of transcriptions and adaptations for viola samples of folk music in order to form own concert and instructional repertoire. A brief overview of the history of viola performance in Kazakhstan has shown that the transcriptional approach has become one of 
the most important trends in the development of creative practice of creating national viola literature. Within the boundaries of this practice, priorities were formed in the selection of samples, and creative approaches and patterns of interpretation of musical works were crystallized.

The analysis of transcriptions created by the Kazakh violist, one of the founders of the national viola school Yakov Fudiman, testifies to a deep reflection on the author's intention and the desire to convey all the facets of its figurative and semantic lines through the sound of the instrument. At the same time, it is important for him to maintain the level of virtuosity of the original, the features of articulation and texture design. Being an excellent violist, he was able to beneficially use the "natural" qualities of the instrument to create a whole gallery of musical images - fullness and warmth of sound, great vibrato capabilities, a special timbre color. His careful and balanced attitude to the creation of transcriptions and adaptations of Kazakh folk melodies and instrumental pieces, kyuis, works of Kazakh composers, demonstrates great attention to detail - tempo notation, fingering and strokes, which made it possible to speak about a peculiar "Fudiman's" approach to solving creative and performing tasks facing the interpreter. At the same time, Fudiman's manner is characterized by an original interpretation of the original source, while preserving the author's intention, making it more accessible to perception.

The theory of creating viola transcriptions covers a whole range of issues related to both the preparatory stage and the direct work on the musical piece. The following are the fundamental principles of transcriptional work:

1. The need to clarify the purpose of transcription;

2. The importance of knowing the nature and capabilities of the instrument for which the transcription is made, in our case - the viola;

3. The importance of understanding the specifics of the instrument for which the original composition was created;

4. Thorough and comprehensive study of the original musical work in order to determine its suitability for transcription;

5. Inseparability of artistic and performing tasks in the process of transcription.

\section{References}

Borodin, B. B. (2006). Phenomenon of piano transcription: experience of a comprehensive study [Doctoral dissertation; Moscow State Conservatory named after P. I. Tchaikovsky]. Moscow.

Dalton, D. (1988). Playing the viola: conversations with William Primrose. Oxford: Oxford University Press.

Darda, V. N. (2014). Genre of viola concert in the works of composers of Mannheim School. Izvestiya Rossiyskogo Gosudarstvennogo Pedagogicheskogo Universiteta im. A. I. Gertsena, 172, 150-155.

Davydov, N. (1982). Methodology of transcribing the instrumental works for bayan. Moscow: Muzyka.

Forbes, W. (1979). The value of transcriptions. The Strad 89 (April 1979): 1115.

Fudiman, Ya. I. (1980). H. Tastanov's “Melody”, G. Zhubanova's “Theme with Variations”, guidance paper. AlmaAta.

Galvin, R. W. (2013). Viola transcriptions: history, rationale, and process, with focus on selected works by August Halm [Doctoral Dissertation; University of California]. Santa Barbara. 
Gorbunov, V. (2004). Russian viola art of the 18th - early 2oth centuries (instrument, scope of use, composer creativity [Doctoral dissertation; Rachmaninov Rostov State Conservatory]. Rostov-na-Donu.

Greenberg, M. (1967). Russian viola literature. Moscow: Muzyka.

Gushchina, L., \& Stoklitskaya, E. (2001). Works of long form. Moscow: Muzyka.

Ivanchey, N. P. (2009). Piano transcription in the Russian musical culture of the 19th century. Rostov-na-Donu: Rostov State Conservatory named after S. V. Rachmaninov.

Karimov, N. Kh. (2007). Works of the Kazakh composers for viola and piano. Almaty: LEM

Karimov, N. Kh. (2010). Kazakhstan's viola school. Sistema Tsennostey Sovremennogo Obshchestva, 16, 85-94.

Klimova, V. V. (2011). Transcriptional work of V. V. Borisovskiy. Molodoy Ucheny, 5(2), 250-252.

Klimova, V. V. (2013). The phenomenon of transcription: terminological aspect. Vestnik Bashkirskogo Universiteta, 18(3), 871-877.

Kogan, G. (1972). On transcription. Moscow: Sovetskiy Kompozitor.

Kurys, J. A. (2016). The art of transcription and its impact on the development of the viola as a solo instrument [Doctoral dissertation; The University of Nebraska]. Lincoln.

Kuznetsov, I. K. (1977). Early piano (clavier) concert. In V. V. Protopopov (ed.), Issues of musical form (pp. 156-185). Moscow: Muzyka.

Lee, H. (2005). The history of viola transcriptions and a comprehensive analysis of the transcription for viola and piano of Beethoven's Violin Sonata Op. 30, No. 1 [Doctoral dissertation; University of Cincinnati, College-Conservatory of Music]. Cincinnati.

Marshanskiy, S. A. (2012). Viola art of Russia of second half of the 2oth - beginning of the 21st century [Doctoral dissertation; Rachmaninov Rostov State Conservatory]. Rostov-na-Donu.

Mazel, L. A., \& Tsukkerman, V. A. (1967). Analysis of the musical works. Moscow: Muzyka.

Mondragon, E. (2018). Re-examining viola transcriptions through informed historical performance [Doctoral dissertation; University of Maryland]. College Park.

Nurbayev, A. (1984). Pieces for violin and kobyz. Alma-Ata: Ener.

Parshin M. (2013). Development of the art of concert balalaika transcription [Doctoral dissertation; Togliatti Conservatory]. Togliatti.

Pchelintsev, A. V. (2018). Academic folk instruments: in search for new sound identity. Yuzhno-Rossiyskiy Muzykalny Almanakh, 2, 52-56. doi: 10.24411/2076-4766-2018-12009

Ponyatkovskiy, S. (2007). The history of the viola art. Moscow: Muzyka.

Reitih, M. (1975). Musical pieces, works of long form, ensembles. Moscow.

Riley, M. W. (1991). The history of the viola. Ann Arbor, Michigan: Braun-Brumfield.

Roizman, L. I. (1973). Piano transcriptions of organ compositions of old masters. Voprosy Fortepiannogo Ispolnitelstva, 3, 155-177.

Sagimbaev, N. E. (2015). The history of viola performance in Kazakhstan. Almaty: Typography KNK named after Kurmangazy.

Yuzefovich, V. (1977). V. V. Borisovskiy - the founder of the Soviet viola school. Moscow: All-Union Publishing House "Sovetskiy Kompozitor."

Zaytseva, M. L., \& Sushkova-Irina, Ya. I. (2018). Viola art: brief history of formation and development. Evraziyskiy Soyuz Uchenykh, 8(53), 18-20. 
Zhumabekova, D. Zh. (2015). Violin culture of Kazakhstan: Pedagogy, performance and composition (from origins to modern times) [Doctoral dissertation; Moscow State Conservatory named after P. I. Tchaikovsky]. Moscow. 